\title{
Production of Hydrogen from Aqueous Phase Reforming of Glycerol: Economic Evaluation
}

\author{
Rodolfo Salazar Pérez ${ }^{1}$, Mariana M. V. M. Souza ${ }^{1}$, Neyda C. Om Tapanes ${ }^{2}$, \\ Gisel Chenard Diaz ${ }^{1}$, Donato A. G. Aranda ${ }^{1}$ \\ ${ }^{1}$ Chemical School, Federal University of Rio de Janeiro (UFRJ), Rio de Janeiro, Brazil \\ ${ }^{2}$ State University of Western of Rio de Janeiro (UEZO), Rio de Janeiro, Brazil \\ Email: rsalazarperez@yahoo.com, neydatapanes@uezo.rj.gov.br
}

Received September 25, 2013; revised October 25, 2013; accepted November 4, 2013

Copyright (C 2014 Rodolfo S. Perez et al. This is an open access article distributed under the Creative Commons Attribution License, which permits unrestricted use, distribution, and reproduction in any medium, provided the original work is properly cited. In accordance of the Creative Commons Attribution License all Copyrights (c) 2014 are reserved for SCIRP and the owner of the intellectual property Rodolfo S. Perez et al. All Copyright (C) 2014 are guarded by law and by SCIRP as a guardian.

\section{ABSTRACT}

Glycerol is the main byproduct from the production of biodiesel by transesterification of vegetable oils, and approximately $10 \%$ of total biodiesel production volume corresponds to glycerol. The profitability of various chemical processes depends, in part, on the sale of byproducts, which enables a reduction in the production costs and consequently, in the product's final price. Thus, it is necessary to look for alternatives to solve the problem of glycerol buildup, in order to avoid future environmental impacts and make biodiesel competitive in the growing market of biofuels. In this context, this study's objective is the development of a low cost and environmental clean technology that allows the conversion of glycerin into a greater value product. In this paper, an economic evaluation of production hydrogen using Aqueous Phase Reforming (APR) was conducted. Firstly, we detailed the technical assumptions in the study. Reactions were performed in batch reformer of 10 liters of capacity, at the temperature of $250^{\circ} \mathrm{C}$ and pressure of $38 \mathrm{~atm}$. Finally, a sensitivity analysis was performed. The results from economic evaluation show that APR of glycerol, using nickel catalysts supported on alumina or zirconium oxide, is a promising and competitive technology for hydrogen production.

\section{KEYWORDS}

Glycerol; Hydrogen; Aqueous Phase Reforming; Economic Analysis

\section{Introduction}

Currently, it is possible to observe a growing number of researchers and experts that relate to the increased emission of greenhouse gases, such as carbon dioxide $\left(\mathrm{CO}_{2}\right)$ and methane $\left(\mathrm{CH}_{4}\right)$, with the increase in mean annual temperature biosphere of the planet, a phenomenon known as global warming. This factor, coupled with the reduction of reserves of fossil energy, the rising price of oil and rising of world energy demand, has encouraged the use of renewable energy and development of different technologies to produce them from renewable sources [1].

In this sense, the application of hydrogen technology is considered by many experts as an alternative option to replace current fossil fuels, due to its very low environmental impacts. However, pure hydrogen is very uncommon in the Earth's atmosphere. It is naturally found in compounds such as water and other organic matter. To produce hydrogen gas, it is necessary to process these compounds [2].

The method currently most used to produce hydrogen is steam reforming of natural gas, reaching half of the world production of hydrogen. This method is established and used since the 30s, with the entry into operation of the first commercial plants in Germany and the United States. The main factor in this wide production is its low cost compared to the gasification of coal and biomass and the electrolysis of water. A disadvantage of the use of natural gas is the considerable amount of emissions of $\mathrm{CO}_{2}$.

Hydrogen production from biomass, waste or byproducts, has been evaluated as one of the most efficient and environmentally interesting productions. 
The sale of glycerin kept prices high and stable between 1998 and 2003, being used in various industries. From 2004 there is an imbalance in the world market due to supply of glycerin new biodiesel plants, mainly in Europe. Considering the large-scale production of biodiesel, currently there is an excess of glycerin in the market. The destination of this glycerin, which is still considered a byproduct of the biodiesel production, is a matter for concern in most mills and, up to now, the main solution for discarding it is burning or export sales. This has led biofuel companies to start considering crude glycerin as a waste that cannot be ignored.

In this context, this study's objective is the development of a low cost and environmental clean technology, which allows producing hydrogen from glycerol, using heterogeneous catalysts.

Nickel and platinum catalysts have a wide industrial application. They have high activity and selectivity in hydrogen production using different raw materials and reactions, such as the hydrocarbons reforming [3], steam reforming of glycerol [4] and ethanol [5], the decomposition of methane to produce hydrogen [6] and Aqueous Phase Reforming (APR) of glycerol [7].

Production of hydrogen by APR of oxygenated organics, like glycerol, provides several economic and technologic advantages compared with steam reforming. The main advantages are: (i) Removal of the vaporization stages of water and raw material to be reformed, significantly reducing the energy demand of the process; (ii) Operation at low temperature, avoiding parallel reactions of decomposition of the oxygenate compounds and promoting the removal reaction of CO (shift reaction), making it possible hydrogen production with a low concentration of carbon monoxide in a single stage; (iii) operational pressure, typically between 15 and 50 atm, which allows that hydrogen can be purified by adsorption or by technology using membranes [8].

These advantages, coupled to the possibility of using renewable raw materials, would be one solution technically and environmentally favorable. Determining whether these proposals are technologically viable is still a topic to be analyzed.

Robinson et al. [9] studied APR of glycerol using as catalysts $20 \%$ of nickel oxide and platinum supported in alumina and zirconium oxide. The catalysts were synthesized by different methods: wet impregnation, co-precipitation and combustion. The catalytic tests showed that platinum and nickel catalysts have potential in the reforming reaction of biomass residues, such as glycerol for the production of hydrogen. In the tests, at $250^{\circ} \mathrm{C}$ and $1 \% \mathrm{v} / \mathrm{v}$ glycerol solution, all of the catalysts used showed high catalytic activity and good stability, and obtained the best conversion of glycerol in the reactions that used synthesized catalysts by the method of wet impregnation (over 50\%) [10].

In this paper, the financial viability of producing hydrogen using APR was evaluated. The study comprises the economic effect of the catalyst, and raw material under the reaction as well as the cost trends.

\section{Methods}

\section{Technical Assumptions for Economical Assessment}

The APR reactions were performed in batch reforming coupled to a gas chromatograph, at temperature of $250^{\circ} \mathrm{C}$, pressure of $38 \mathrm{~atm}$ and using heterogeneous catalyst. The supported metal catalysts used were: platinum on alumina $\left(\mathrm{Pt} / \mathrm{Al}_{2} \mathrm{O}_{3}\right)$ nickel on alumina $\left(\mathrm{Ni} / \mathrm{Al}_{2} \mathrm{O}_{3}\right)$, platinum on zirconia $(\mathrm{Pt} / \mathrm{ZrO})$ nickel on zirconia $(\mathrm{Ni} / \mathrm{ZrO})$. The product quality was defined as the pure hydrogen $\left(\mathrm{H}_{2}\right)$.

Fitting the quality of biomass used as feedstock and the quality the final product were evaluated four technological variants for study the economic feasibility of APR of glycerol to produce pure hydrogen using each catalyst defined previously. The characteristics of crude glycerin used as raw material are shown in Table 1.

The sequence of economic analysis is detailed below:

- Quantify the parameters for the calculation of the initial investment cost, cost of operation and maintenance cost inputs for the four technological variables defined.

- Estimate the revenue and profit tax for each variant technology.

- Determine the economic projections of results through the Income Statement and Cash Flow in a 10year projection of life.

- From this cash flow determine financial ratios that demonstrate the financial viability of the technology: Net Present Value (NPV), Internal Rate of Return (IRR), Payback period (PB) and other indicators.

- Perform the sensitivity analysis of the variation of operating parameters and costs for the definition of critical parameters.

Table 1. Characteristics of crude glycerin.

\begin{tabular}{cccc}
\hline Parameters & Methodology & Specification & Value \\
\hline Sulfated Ash, \% m/m & ASTM D874 & $2.5 \mathrm{max}$ & 7.3 \\
NaCl, \% m/m & AOCS Ea 2 - 38 & $7 \mathrm{max}$ & 5.37 \\
Methanol, \% m/m & MI & $0.2 \mathrm{max}$ & 0.002 \\
Moisture, \% m/m & MI & $15 \mathrm{max}$ & 12.8 \\
MONG, \% m/m & ISSO 2464 & $1.5 \mathrm{max}$ & 0.0 \\
Glycerol, \% m/m & AOCS Ea 6 - 94 & $80 \mathrm{~min}$ & 80.41 \\
Density at 20 C, g/l & MI & 1.2 to 1.3 & 1.26 \\
Acid Value, \% FFA & AOCS Cd 3d - 63 & 2 max & 1.1 \\
\hline
\end{tabular}




\section{Results and Discussion}

\subsection{The Total Project Investment}

The total project investment includes purchased- equipment costs, the total installed cost and indirect costs. Table 2 shows technical characteristics required for the reformer and the total project investment of the process.

\subsection{Operation Costs}

There are two kinds of operating costs: fixed and variable costs. The variable operating cost used in this analysis include raw materials (crude glycerin and catalyst), utilities (electricity and gas drag). The fixed operating costs include maintenance, labor cost, depreciation and insurance \& taxes.

\section{- Raw materials cost (crude glycerin)}

Theoretically, the APR of glycerol provides a link between the consumption of raw materials and the production of hydrogen. Considering the use of $90 \%$ of the capacity of the reformer in each batch of reform were used 9 liters of aqueous solution containing $10 \%$ glycerol. The operation time of the system was average 12 hours per day, totalized 3960 hours per year. On these conditions, the consumption rate of crude glycerin is given by Equation (1) [10]:

$$
I C_{c g}=V * F C * C_{c g} * d_{c g} * t(100 \%)=340.2 \mathrm{kgy}
$$

where

$I_{C G}$ : Consumption rate of CG $(\mathrm{kg} / \mathrm{d}$ ou $\mathrm{kg} / \mathrm{y})$

$V$ : Capacity of the reformer $=10 \mathrm{l}$

$F C$ : Factor of capacity of reformer $=0.9$

$C_{C G}$ : Concentration of glycerol $=0.1 \%$

$d_{C G}$ : Density of CG $=1.26 \mathrm{~kg} / \mathrm{l}$

$t$ : Operating time of the reformer $=300 \mathrm{~d} / \mathrm{y}$.

Considering the commercial value of the crude glyce-

Table 2. Technical characteristics required for the reformer.

\begin{tabular}{cc}
\hline Production capacity, with tailstock & 10 litres, \\
\hline Capacity factor & $90 \%$ \\
Sealing gasket with flexible graphite & a $500^{\circ} \mathrm{C}$ \\
Magnerial & Stainless steel T316SS \\
Engine, Variable speed & 16in-lb, stainless steel \\
Manometer, pressure transducer & $1 / 4$ hp \\
Temperature controller, including: & $0-3000$ psi \\
TDM, PDM and HTM & PID \\
H2 pressure generated & 4 bar \\
Price ${ }^{*}$ R\$ & R\$ 170.00000 \\
\hline
\end{tabular}

"Price included service of commissioning of the equipment. rin 0.5 U.S. $\$ / \mathrm{kg}$, raw material cost is U.S. \$ 170.1/y.

\section{- Raw materials cost (catalyst)}

The reactions were performed using 0.8 grams catalyst per liter of solution. In the calculus that follows, was assumed that the replacement time of the catalyst is 6 days (reaction time $=72 \mathrm{~h}$ ).

$$
I C_{\mathrm{cat}}=V * F C * C c a t=7.2 g 6 d
$$

where:

$$
I C_{\text {cat }} \text { : Consumption rate of catalyst (g/6 d) }
$$$$
C_{\text {cat }}: \text { Catalyst concentration }=0.8 \mathrm{~g} / \mathrm{l}
$$

This represents an annual consumption of $360 \mathrm{~g}$ of catalyst. Table 3 shows the unit prices and costs corresponding annual purchasing each catalyst [10].

\section{- Utilities (electricity and gas drag)}

The electric consumption was determined by Equation (3):

$$
I C_{\text {elt }}=C_{\text {elt }} * t b * t=792.0 \mathrm{kWhy}
$$

where:

$I C_{\text {elt }}$ : Electric consumption rate per year

$C_{\text {elt }}$ : Electric consumption $(\mathrm{kWh})=0.22 \mathrm{kWh}$

$t b$ : Reaction time of batch $=12 \mathrm{~h}$

The price of electricity for the commercial sector and service at $\mathrm{R} \$ 0.2797 / \mathrm{kWh}$, resulting in annual electrical cost R \$ 221.50/y.

Gas drag consumption, another utility of the process, is $30 \mathrm{~mL} / \mathrm{min}$, after 12 hour totalized $0.0216 \mathrm{~m}^{3}$. Considering the helium price of $60 \mathrm{R} \$ / \mathrm{m}^{3}$ the total cost of Gas drag is of $427.7 \mathrm{R} \$ / \mathrm{y}$.

\section{- Labor and maintenance cost}

The annual Labor and maintenance cost of the system was considered to be $40 \%$ of the annual cost of raw materials and inputs (glycerol and catalyst). This is considered a default value according to DOE [11].

Figure 1 shows the comparison between the percentage values of costs raised by the analysis of cash flow for the implementation of technology, considering a reformer useful life of 10 years.

\section{- Depreciation expense}

In the paper were used the straight-line depreciation method. This method calculates depreciation by spreading the cost evenly over the life of the fixed asset. The depreciation rate was:

- For equipment, facilities, materials, furniture and

Table 3. Catalyst costs.

\begin{tabular}{cccc}
\hline Catalyst & $\begin{array}{c}\text { Consumption rate of } \\
\text { catalyst }(\mathrm{g} / \mathrm{y})\end{array}$ & $\begin{array}{c}\text { Unit Cost } \\
(\mathrm{R} \$ / \mathrm{g})\end{array}$ & $\begin{array}{c}\text { Total Cost } \\
(\mathrm{R} \$ / \mathrm{y})\end{array}$ \\
\hline $\mathrm{Pt} / \mathrm{Al}_{2} \mathrm{O}_{3}$ & 360 & 17.5 & 6307.2 \\
$\mathrm{Ni} / \mathrm{Al}_{2} \mathrm{O}_{3}$ & 360 & 4.0 & 1440.0 \\
$\mathrm{Pt} / \mathrm{ZrO}$ & 360 & 28.0 & 10080.0 \\
$\mathrm{Ni} / \mathrm{ZrO}$ & 360 & 10.0 & 3600.0 \\
\hline
\end{tabular}




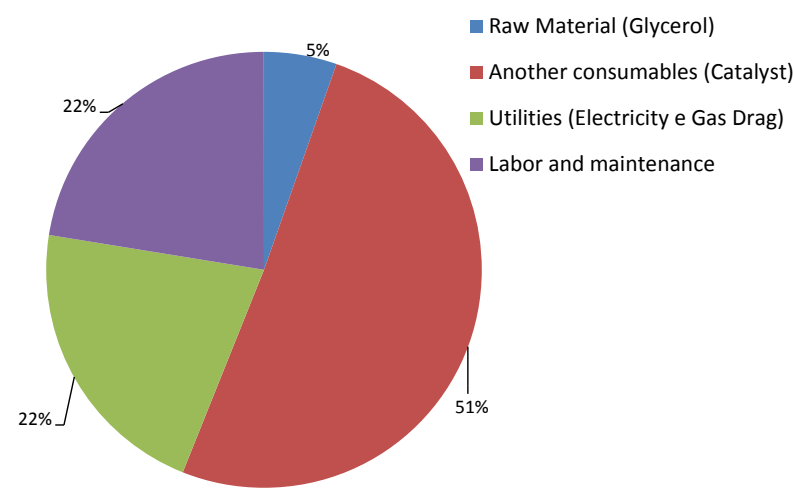

Figure 1. Summary of the operating costs of cash flow.

other fixtures-10\% of the asset's cost;

- For construction and another services- $4 \%$ of the amount spent.

\subsection{Operational Revenue}

The operational revenue is according of sales hydrogen in cylinders and trailers with deposits with standard pressures of the order of 150 to 400 bar.

The price of hydrogen cylinder with capacity of $10 \mathrm{~m}^{3}$, at 200 bar with quality Tech, is R\$ 1200 , then the price of hydrogen is $\mathrm{R} \$ 120 / \mathrm{m}^{3}$ or $\mathrm{R} \$ 0.12 / \mathrm{l}$. With this information was estimated the price of purified hydrogen.

The amount of produced hydrogen depends of the type of raw material, of the catalyst used and of the level of product purity. For the calculations were used theoretical yields, defined by the stoichiometry of the reforming reaction. Considering that are processed per day $1.134 \mathrm{~kg}$ of Glycerol in Table 4 are shown the theoretical stoichiometric yield, production per day and revenues for each variant reaction.

It can be observed in the previous table that the highest revenue is obtained with the variant that uses a catalyst $\mathrm{Ni} / \mathrm{Al}_{2} \mathrm{O}_{3}$, followed by $\mathrm{Ni} / \mathrm{ZrO}$. This result is expected because are the catalysts of lower price and higher theoretical yield.

\section{Economic Analyses}

A comparative analysis between the production cost and the price of hydrogen produced in each variants technology shows a significant difference that can be considered as an apparent gain (Figure 2). This difference is largest in the variants using the supported nickel catalyst. Logical result considers the difference in price between the nickel and platinum catalysts.

This apparent benefit is corroborated by positive values of EBITDA and Net Profits of each variant. However, in assessing the financial indicators NPV, IRR and Payback possible identify the influence of the investment on the economic viability of the technology.

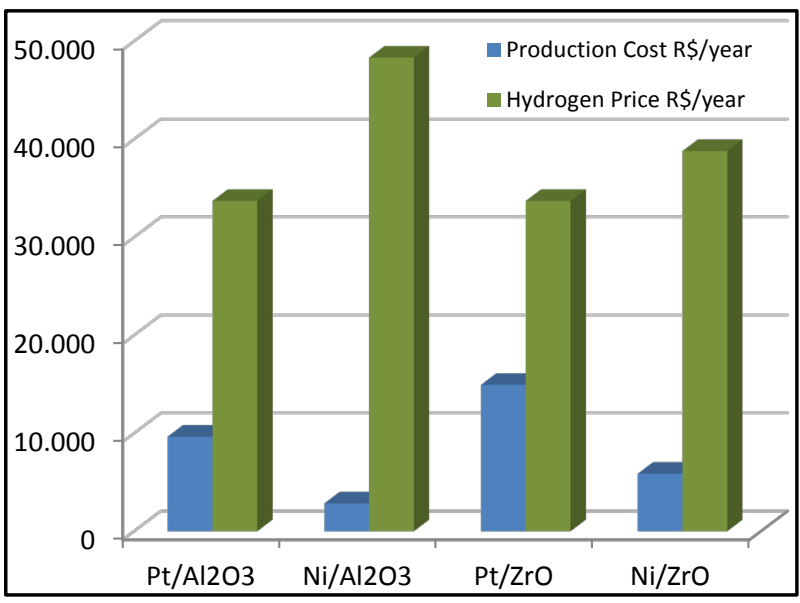

Figure 2. Comparison between the hydrogen price and the hydrogen production cost by APR of glycerol.

Table 4. Operational revenue of APR reaction ( $R \$ / y)$.

\begin{tabular}{cccc}
\hline & \multicolumn{2}{c}{ Production of $\mathrm{H}_{2}$} & \\
\cline { 2 - 3 } Catalyst & $\mathrm{kg} / \mathrm{kg}$ de glycerol & $\mathrm{l} / \mathrm{d}$ & \\
\cline { 2 - 3 } $\mathrm{Pt} / \mathrm{Al}_{2} \mathrm{O}_{3}$ & 0.106 & 1337.09 & 48135.24 \\
$\mathrm{Ni} / \mathrm{Al}_{2} \mathrm{O}_{3}$ & 0.152 & 1917.33 & 69023.88 \\
$\mathrm{Pt} / \mathrm{ZrO}$ & 0.106 & 1337.09 & 48135.24 \\
$\mathrm{Ni} / \mathrm{ZrO}$ & 0.122 & 1538.91 & 55400.76 \\
\hline
\end{tabular}

Conceptually, the breakeven point is the point at which sales revenues and production costs are equal, in other words, is the point of zero profit from the venture. Analyzing the results of NPV (Figure 3) is possible observe that only the technological variants with nickel catalysts supported reach positive values of NPV before of the 10-year.

In Table 5 is added the concept of perpetuity to calculate the NPV and is identified the value of the enterprise. The results show that the reaction using catalysts Pt/ $\mathrm{Al}_{2} \mathrm{O}_{3}$ reaches equilibrium after 12 years of operation (Figure 4).

The perpetuity is the present value of future cash flows (stable period)-where the periodic of payments begin on a fixed date and continue indefinitely-that is, the method includes the expectation of business continuity. The PV of perpetuity is calculated from the Equation (4).

$$
P V \text { perpetuity }=A / r
$$

where,

PV perpetuity: Present Value of the Perpetuity

A: fixed periodic payment

r: interest rate or discount rate per compounding period.

The calculation of financial indicators, shown briefly in Table 6, confirms the results already mentioned.

Based on the assumptions made for the research, it can 


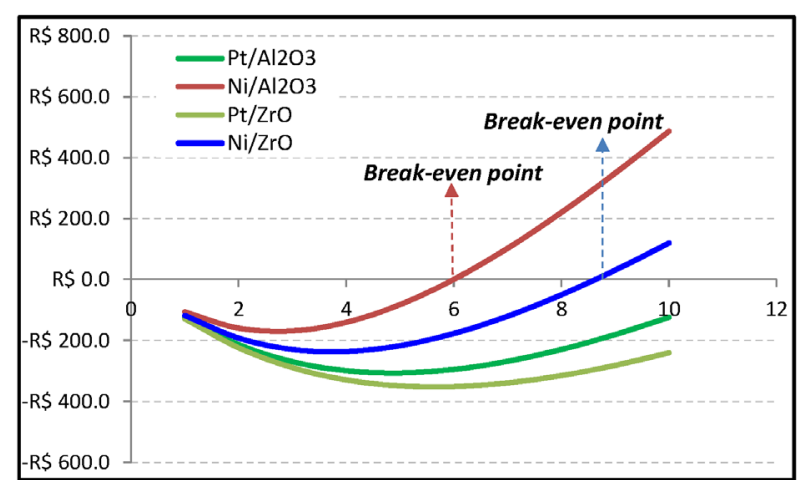

Figure 3. NPV results in the reactions of APR of glycerol using different catalysts $(\mathrm{R} \$ / \mathrm{y})$.

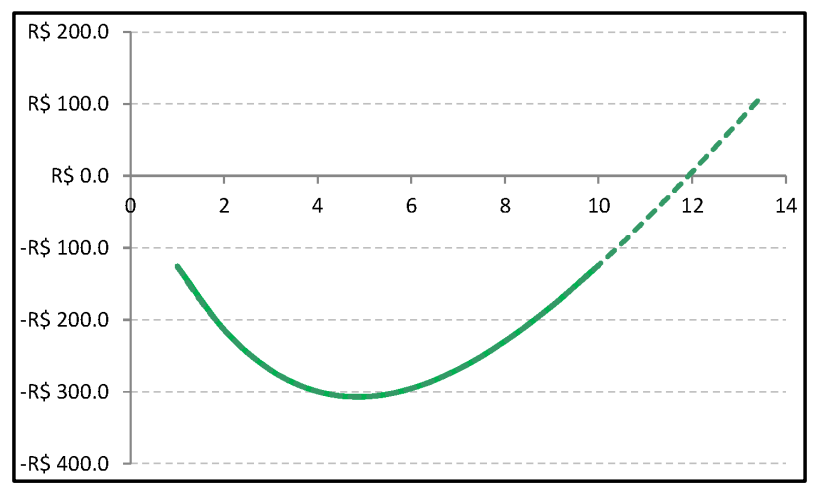

Figure 4. Projection of NPV considering the perpetuity for the reaction with $\mathrm{Pt} / \mathrm{Al}_{2} \mathrm{O}_{3}$ as catalyst.

Table 5. Perpetuity and NPV considering the perpetuity.

\begin{tabular}{ccc}
\hline Catalyst & Perpetuity (R\$) & $\mathrm{NPV}_{\text {perpetuity }}(\mathrm{R} \$)$ \\
\hline $\mathrm{Pt} / \mathrm{Al}_{2} \mathrm{O}_{3}$ & $\mathrm{R} \$ 566600$ & $\mathrm{R} \$ 74339.54$ \\
$\mathrm{Ni} / \mathrm{Al}_{2} \mathrm{O}_{3}$ & $\mathrm{R} \$ 1378330$ & $\mathrm{R} \$ 970173.82$ \\
$\mathrm{Pt} / \mathrm{ZrO}$ & $\mathrm{R} \$ 411833$ & $-\mathrm{R} \$ 96463.04$ \\
$\mathrm{Ni} / \mathrm{ZrO}$ & $\mathrm{R} \$ 890548$ & $\mathrm{R} \$ 431851.79$ \\
\hline
\end{tabular}

Table 6. Financial indicators of economic evaluation.

\begin{tabular}{ccccc}
\hline & $\mathrm{Pt} \mathrm{Al}_{2} \mathrm{O}_{3}$ & $\mathrm{Ni} / \mathrm{Al}_{2} \mathrm{O}_{3}$ & $\mathrm{Pt} / \mathrm{ZrO}$ & $\mathrm{Ni} / \mathrm{ZrO}$ \\
\hline Profit Margin & $44.65 \%$ & $61.64 \%$ & $36.32 \%$ & $53.96 \%$ \\
ROI & $22.64 \%$ & $38.93 \%$ & $19.53 \%$ & $29.14 \%$ \\
Payback (year) & $>10$ & 6 & $>10$ & 9 \\
IRR & $13.10 \%$ & $43.91 \%$ & $5.60 \%$ & $26.13 \%$ \\
\hline
\end{tabular}

be seen that the reactions catalyzed by platinum supported on alumina and oxide zirconium (marked in red) are not profitable. The negative NPV in these reactions means that the cash flow for the 10 projected years is negative, not possible to afford the investment in defined time. The Table 6 also shows that the IRRs are low compared with the discount rate (10\%).

The IRR determines the time the investment is paid, if this ratio is less than the discount rate $(10 \%)$, means that has not been paid the amount invested. The indication of the economic viability of a project is demonstrated when the IRR of the project is shown above the appropriate discount rate to the enterprise

\section{Sensitivity Analysis}

Economic decisions are rarely taken in conditions of absolute certainty. The uncertainties in decision-making can lead to risks, which can affect the viability of the project.

According KAPLAN [12], the sensitivity analysis is one of the possible approaches for assessing the uncertainties of an enterprise. Sensitivity analysis is a technique for simulating simple but very useful. The analysis is done using as variables the most uncertain parameters, such as projected revenues, costs of major inputs and the discount rate. The traditional technique is to vary the value of a given parameter at $10 \%$ or $20 \%$ around the arbitrated value to the flow box of reference. The effect of each parameter must be analyzed separately. Calculate the result of the decision parameter (NPV and IRR) and compared the results.

The parameters whose variations are more significant should be analyzed more carefully. In this study, the sensitivity analysis was used to determine the variations of greater influence and determine how to improve the outcome of variants less profitable.

Sensitivity analyzes of the production cost of hydrogen generated by APR of glycerol were performed from:

- Variation of the cost of the catalyst

- Cost of raw material

- Sales price of hydrogen

Were determined three financial indicators that allowed to define which parameter significantly influences on the economic viability of the reactions studied, these were: NPV, IRR and EBITDA. The main results are shown in Figures 5-7. Note that the reaction using catalyst $\mathrm{Pt} / \mathrm{ZrO}$ was not plotted due to low values of IRR, NPV and EBITDA observed during the sensitivity analysis.

Sensitivity analysis can to determine which factors in a risk model contribute most to the variance in the risk estimate. The Variable Price of Hydrogen contributes significantly on viability of the reaction. The variations of the cost of catalyst and raw material have no significant influence on the TIR effect. The first result is due to the small amount of catalyst that is used in the reaction and the second result is due to the low price of glycerol for being a co-product reusable.

The sensitivity analysis showed that the variation of the parameters evaluated did not have significant influ- 


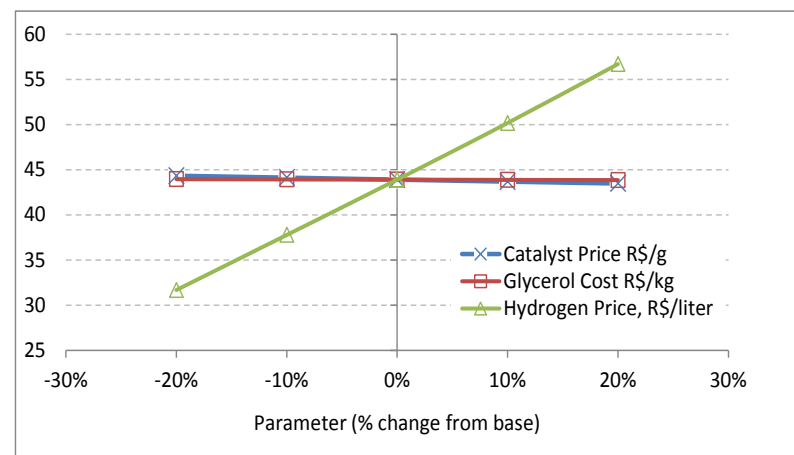

Figure 5. Sensitivity analysis with respect to IRR of the APR reaction using catalyst of $\mathrm{Ni} / \mathrm{Al}_{2} \mathrm{O}_{3}$.

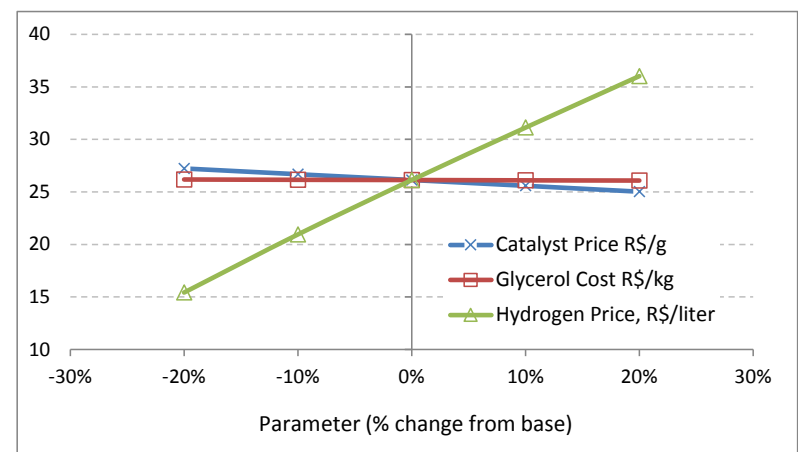

Figure 6. Sensitivity analysis with respect to IRR of the APR reaction using catalyst of $\mathrm{Ni} / \mathrm{ZrO}$.

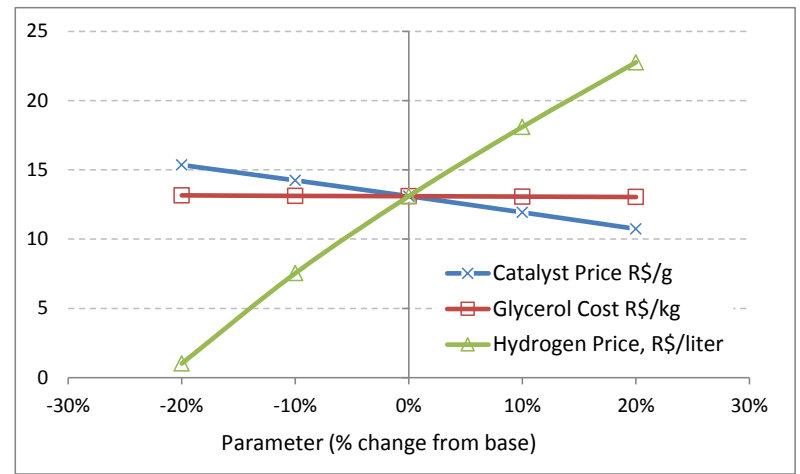

Figure 7. Sensitivity analysis with respect to IRR of the APR reaction using catalyst of $\mathrm{Pt} / \mathrm{Al}_{2} \mathrm{O}_{3}$.

ence on the feasibility of reaction. It is assumed that this effect is due to the low theoretical yield of the reaction (0.05 $\mathrm{gH}_{2}$ /g raw material).

\section{Conclusions}

In this paper, we obtained the results of the economic analysis of the technology of Aqueous Phase Reforming for hydrogen production, using as a biomass feedstock residual glycerol. The information used for financial evaluations was obtained from a market survey and theoretical and experimental test, showing that the pro- ject is technically and economically feasible, depending on the type of catalyst used. The reactions with nickel catalysts supported on alumina and zirconium showed the highest viability (IRR $>10 \%$ and high NPV). It is noteworthy that this viability doesn't embed any tax incentives or price protected.

The sensitivity analysis method showed that the most significant operational parameter on the viability of the process is the final product price. However, the variation of this parameter did not improve the viability of APR of glycerol using platinum catalyst supported on zirconium.

The proposal to use glycerol, as raw material for the production of hydrogen, and attractive results for the industry and the market, were evaluated in this study. However, the proposed technology can be applied to other biomass-derived polyols (Ex mannitol and erythritol).

\section{Acknowledgements}

The authors would like to convey thanks to the Carlos ChagasFilho Foundation for Research Support of Rio de Janeiro State (FAPERJ) for providing the financial support.

\section{REFERENCES}

[1] R. H. Perry, D. W. Green and J. O. Maloney, "Perry’s Chemical Engineers' Handbook," McGraw-Hill, New York, 1997.

[2] R. Aguilar, J. A. Ramirez, G. Garrote and M. Vazquez, "Kinetic Study of the Acid Hydrolysis of Sugar Cane Bagasse,” Journal of Food Engineering, Vol. 55, No. 4, 2002, pp. 309-318. http://dx.doi.org/10.1016/S0260-8774(02)00106-1

[3] N. N. Nichio, M. L. Casella, G. F. Santori, E. N. PonzI and O. A. Ferretti, "Stability Promotion of $\mathrm{Ni} / \gamma-\mathrm{Al}_{2} \mathrm{O}_{3}$ Catalysts by Tin Added via Surface Organometallic Chemistry on Metals, Application in Methane Reforming Processes," Catalysis Today, Vol. 62, No. 2-3, 2000, pp. 231-240. http://dx.doi.org/10.1016/S0920-5861(00)00424-7

[4] S. Adhikari, S. D. Fernando and A. Haryanto, "Hydrogen Production from Glycerin by Steam Reforming over Nickel Catalysts,” Renew Energy, Vol. 33, No. 5, 2008, pp. 1097-1100. http://dx.doi.org/10.1016/j.renene.2007.09.005

[5] J. D. A. Bellido and E. M. Asaf, "Nickel Catalysts Supported on $\mathrm{ZrO}_{2}, \mathrm{Y}_{2} \mathrm{O}_{3}$-Stabilized $\mathrm{ZrO}_{2}$ and CaO-Stabilized $\mathrm{ZrO} 2$ for the Steam Reforming of Ethanol: Effect of the Support and Nickel Load", Journal of Power Sources, Vol. 177, No. 1, 2008, pp. 24-32. http://dx.doi.org/10.1016/j.jpowsour.2007.11.006

[6] Y. Li, B. Zhang, X. Tang, Y. Xu and W. Shen, "Hydrogen Production from Methane Decomposition over $\mathrm{Ni} / \mathrm{CeO} 2$ Catalysts," Catalysis Communications, Vol. 7, No. 6, 2006, pp. 380-386. 
http://dx.doi.org/10.1016/j.catcom.2005.12.002

[7] R. L. Manfro, "Produção de Hidrogênio a partir da Reformaemfaseliquida do Glicerol e do Hidrolisado de Bagaço de Cana de Açúcar,” Master Dissertation, Federal University of Rio de Janeiro, Rio de Janeiro, 2009.

[8] R. R. Davda, J. W. Shabaker, G. W. Huber, R. D. Cortright and J. A. Dumesic, "A Review of Catalytic Issues and Process Conditions for Renewable Hydrogen and Alkanes by Aqueous-Phase Reforming of Oxygenated Hydrocarbons over Supported Metal Catalysts,” Applied Catalysis B: Environmental, Vol. 56, No. 1-2, 2005, pp. 171-186. http://dx.doi.org/10.1016/j.apcatb.2004.04.027

[9] R. L. Manfro, A. F. Costa, N. F. P. Ribeiro and M. M. V. M. Souza, "Hydrogen Production by Aqueous-Phase Reforming of Glycerol over Nickel Catalysts Supported on
CeO2," Fuel Processing Technology, Vol. 92, No. 3, 2011, pp. 330-335.

http://dx.doi.org/10.1016/j.fuproc.2010.09.024

[10] Sigma Aldrich, “Reagent Grade,” 2009.

www.sigmaaldrich.com

[11] US Department of Energy, "Cost and Performance Comparison of Stationary Hydrogen Fueling Appliances,” The Hydrogen Program Office of Power Technologies, 2002. http://www1.eere.energy.gov/hydrogenandfuelcells/pdfs/ 32405b2.pdf

[12] B. Muthen and D. Kaplan, "A Comparison of Some Methodologies for the Factor Analysis of Non-Normal Likert Variables,” British Journal of Mathematical and Statistical Psychology, Vol. 38, 1985, pp. 171-189.

http://dx.doi.org/10.1111/j.2044-8317.1985.tb00832.x 